Original Article

\title{
Comparison between smartphone pedometer applications and traditional pedometers for improving physical activity and body mass index in community-dwelling older adults
}

\author{
Shirley S.M. Fong, PT, PhD ${ }^{1)^{*}}$, Shamay S.M. Ng, PT, PhD ${ }^{2)}$, Yoyo T.Y. Cheng, PT, MSc ${ }^{1)}$, \\ Joni Zhang, BSc ${ }^{1)}$, Louisa M.Y. Chung, DHSc ${ }^{3)}$, Gary C.C. Chow, MSc ${ }^{1,4)}$, \\ Yvonne T.C. Chak, RSW, MASW ${ }^{5}$, Ivy K.Y. Chan, RSW, MSW'), Duncan J. Macfarlane, PhD ${ }^{1)}$ \\ 1) Institute of Human Performance, The University of Hong Kong: Pokfulam, Hong Kong \\ 2) Department of Rehabilitation Sciences, The Hong Kong Polytechnic University, Hong Kong \\ 3) Department of Health and Physical Education, The Hong Kong Institute of Education, Hong Kong \\ 4) Faculty of Liberal Arts and Social Sciences, The Hong Kong Institute of Education, Hong Kong \\ 5) Elderly Core Business, Hong Kong Christian Service, Hong Kong \\ 6) Bliss District Elderly Community Centre, Active Ageing Service, Hong Kong Christian Service, \\ Hong Kong
}

\begin{abstract}
Purpose] The effectiveness of a smartphone pedometer application was compared with that of a traditional pedometer for improving the physical activity and weight status of community-dwelling older adults. [Subjects and Methods] This study had a nonequivalent pretest-posttest control group design. Ninety-seven older adults (mean age $\pm \mathrm{SD}, 60.1 \pm 5.5$ years) joined the smartphone pedometer group and underwent a 2-week walking intervention based on a smartphone pedometer application. Fifty-four older adults (mean age $\pm \mathrm{SD}, 65.3 \pm 8.7$ years) joined the traditional pedometer group and underwent a 2-week walking intervention based on a traditional pedometer. The participants' physical activity was evaluated using the International Physical Activity QuestionnaireShort Form, and their weight status was quantified by calculating the body mass index. The daily pedometer count was also documented. [Results] No significant time, group, or time-by-group interaction effects were found for any of the outcome variables. However, trends of improvement in physical activity and body mass index were seen only in the smartphone pedometer group. [Conclusion] A smartphone pedometer application might be more favorable than a traditional pedometer in improving physical activity and body mass index in community-dwelling older adults. However, further experimental studies are necessary to confirm the results.

Key words: Mobile technology, Walking, Elderly
\end{abstract}

(This article was submitted Jan. 18, 2016, and was accepted Feb. 6, 2016)

\section{INTRODUCTION}

Increased physical activity is known to be associated with a risk reduction for many chronic illnesses such as coronary heart disease, hypertension, stroke, type 2 diabetes, osteoporosis, and cancer ${ }^{1,2)}$. For older adults, increased physical activity has additional benefits such as a decreased fear of falling ${ }^{3)}$ and can actually prevent falls ${ }^{2}$. Thus, how can physical activity be increased? Many previous studies have suggested the use of a pedometer as a motivational tool to increase physical activity and improve health in both younger and older adults ${ }^{1,2)}$. However, there were compliance problems; participants would

\footnotetext{
*Corresponding author. Shirley S.M. Fong (E-mail: smfong@hku.hk)

(C)2016 The Society of Physical Therapy Science. Published by IPEC Inc.

This is an open-access article distributed under the terms of the Creative Commons Attribution Non-Commercial No Derivatives (by-nc-nd) License $<$ http://creativecommons.org/licenses/by-nc-nd/4.0/>.
} 
sometimes forget to put on the pedometer, which is an additional piece of equipment, at the beginning of the day, and the pedometer would sometimes fall off and become lost when the participant undressed ${ }^{4,5}$. Thus, new motivational tools or instruments that can be incorporated into daily use (e.g., smartphone applications) have been developed to enhance adults' physical activity ${ }^{6-9)}$.

The number of smartphone users has increased dramatically in recent years. Approximately $63.5 \%$ of the world's population used smartphones in 2014, according to statistics from eMarketer ${ }^{10)}$. Smartphone applications have become part of our daily lives. Despite the many types of physical harm (e.g., neck pain, muscle fatigue in the upper trapezius, and carpal tunnel changes) associated with the overuse or misuse of smartphones and their applications ${ }^{1-15}$, this technology could be useful in promoting healthy active lifestyles if used correctly ${ }^{6-9)}$. Specifically, a simple smartphone pedometer application can raise awareness about physical activity and increase the amount of walking during adults' normal everyday activities ${ }^{8)}$. It can induce positive behavioral changes in habitual physical activity and thus improve health ${ }^{9,16}$. In addition, the evidence of a cascade effect involving the families and communities of the users of the smartphone pedometer application was noticed ${ }^{17)}$. From a practical standpoint, the use of a smartphone pedometer application to log in physical activity requires no additional equipment; hence, people will not forget to carry it. Most encouragingly, many smartphone pedometer applications have attractive appearances and are free of charge.

Despite the many benefits and advantages associated with the use of smartphone pedometer applications, no study has investigated the effectiveness of the new smartphone pedometer technology relative to that of the traditional pedometer, in the enhancement of physical activity and health in adults, particularly in older adults who are physically less active ${ }^{18)}$. Thus, the aim of this study was to compare the effectiveness of a smartphone pedometer application with that of a traditional pedometer and to assess the improvement of the habitual physical activity and weight status of community-dwelling older adults.

\section{SUBJECTS AND METHODS}

This study used a nonequivalent pretest-posttest control group design. Eligible participants joined either the smartphone pedometer group or the traditional pedometer group as they wished (i.e., no randomization). In addition, the outcome assessors were not blinded to the group assignment. Ethical approval was obtained from the Human Research Ethics Committee of the University of Hong Kong. The study was explained to each participant, and written informed consent was obtained before data collection. All procedures were conducted in accordance with the Declaration of Helsinki (1975, revised 1983).

Older adults were recruited from the Hong Kong Christian Service Bliss District Elderly Community Centre and the local community, via convenience sampling. The inclusion criteria were as follows: (1) an age of 50 years or more, (2) the ability to ambulate independently through indoor and outdoor environments, without the use of a walking aid, and (3) the ability to communicate effectively with others. The exclusion criteria were as follows: (1) medical instability (e.g., uncontrolled hypertension), (2) a significant musculoskeletal disorder (e.g., symptomatic arthritis), (3) a neurologic disorder (e.g., stroke), (4) cardiopulmonary disease, and (5) cognitive impairment. In addition, all participants were screened using the Physical Activity Readiness Questionnaire to ensure that they could safely perform physical activity.

The participants in both groups were enrolled in a 2-week walking intervention in which they were encouraged to walk to different places (e.g., market, parks, and elderly community center) and around the neighborhood using a pedometer (either a smartphone pedometer application or a traditional pedometer).

For the smartphone pedometer application-based walking intervention, the research personnel assisted the participants who joined the smartphone pedometer group to download and set up a free pedometer application (e.g., Pedometer Lite, Pedometer++, and WalkLogger) on their smartphones. The mobile pedometer application logged the number of steps they walked per day. The participants were instructed to carry the same mobile phone in their pocket for two consecutive weeks from the moment they got up to the end of the day, just before they went to bed (except when showering). In addition, they were taught how to record and reset the number of steps aggregated at the end of each day and document the step count in a logbook (record form).

For traditional pedometer-based walking intervention, the participants in the traditional pedometer group were given a pedometer (Ariel Premium Supply, Inc., St. Louis, USA) that registered the number of steps they took each day. They were shown how to attach the pedometer to a belt fixed around the left iliac crest level and how to record and reset the number of steps aggregated at the end of each day. The participants were instructed to wear the pedometer from the moment they got up and to detach it at the end of the day, just before they went to bed (except when showering). In addition, they were asked to document the number of steps taken, in a logbook (record form), and to push the reset button at the end of each day.

Data collection was performed at the Hong Kong Christian Service Bliss District Elderly Community Centre and in the community by BSc (Exercise and Health) students from the University of Hong Kong under the supervision of two registered physiotherapists and a social worker. All participants were assessed twice -1 to 2 days before the start of the pedometer intervention (pretest) and 1 to 2 days after it ended (posttest). Demographic information including medical history was obtained by interviewing the participants. All participants underwent the tests mentioned bellow.

The International Physical Activity Questionnaire-Short Form (IPAQ-SF, self-administered version) was used to assess the habitual physical activity of the participants during the previous 7 days. The IPAQ-SF is a reliable and valid instrument for measuring physical activity in older adults ${ }^{19,20)}$. The participants were asked to report the frequency (in days per week) 
and duration (in minutes) of walking, all vigorous and moderate activities that lasted for a minimum of 10 minutes, and the time spent on sedentary activity in the past 7 days. The IPAQ-SF data were then converted to a metabolic equivalent score (in MET-minutes per week), for each type of activity using the following formula: MET score of the activity $\times$ minutes of activity per day $\times$ days per week. The MET score assigns each type of activity a weight based on its energy expenditure, assuming 3.3 METs for walking, 4.0 METs for moderate activity, and 8.0 METs for vigorous activity. The total activity score (in MET-minutes per week), that is, the sum of the MET scores of walking, moderate, and vigorous activities, was used for the analysis (a primary outcome measure) ${ }^{20)}$.

The participants' body weight (in kilogram) and height (in centimeter) were measured in light clothing using a bathroom scale and a cloth measuring tape, respectively. The body mass index (BMI) was calculated as body weight (kg) divided by height squared $\left(\mathrm{m}^{2}\right)$. This index is an important indicator of weight and health because of its relationship to mortality in the elderly population ${ }^{21)}$ and was thus used for analysis (as a primary outcome measure).

A smartphone pedometer application (smartphone pedometer group) or a traditional pedometer (traditional pedometer group) was used to enhance the walking intervention and monitor the daily physical activity level of each participant. Subjects were instructed to carry the smartphone or wear the pedometer during the 2-week walking intervention period, as mentioned above. They documented in a logbook the number of steps aggregated at the end of each day ${ }^{22}$. The average pedometer count (in steps per day) over the 2-week intervention period was used for analysis (a secondary outcome measure).

Descriptive statistics (e.g., mean \pm standard deviation) were used to analyze all demographic data and primary and secondary outcome variables. Independent t-tests (for continuous data) and chi-square tests (for categorical data) were used to compare at baseline, the demographic and outcome variables between the two groups. Two-way repeated-measures analysis of covariance was conducted to compare the effects of the two types of pedometers on each primary outcome measure. The within-subject factor was time (two levels), and the between-subjects factor was group (two levels). The relevant demographic and baseline variables that showed significant between-group differences were entered as covariants in the analysis of covariance. The intention-to-treat principle (last observation carried forward) was used to handle missing data resulting from dropouts ${ }^{23}$. In addition, an independent t-test was used to compare the average pedometer count between the two groups. All statistical analyses were performed with SPSS version 20.0 software (IBM, Armonk, NY, USA). The alpha level was set at 5\% (two-tailed).

\section{RESULTS}

From January to April 2015, more than 160 older adults were screened by our assessors to determine their suitability for voluntary participation in the study. Finally, 97 participants joined the smartphone pedometer group, and 54, the traditional pedometer group. Seven participants $(7.2 \%)$ in the smartphone pedometer group and five $(9.3 \%)$ in the traditional pedometer group dropped out. The reasons for attrition in the smartphone pedometer group were an inability to commit the time $(\mathrm{n}=2)$ and loss to follow-up $(n=5)$, and the reasons in the traditional pedometer group were the loss of the pedometer $(n=4)$ and an inability to commit the time $(\mathrm{n}=1)$. Excluding the drop-out cases, the self-reported intervention compliance rate of both groups was $100 \%$. Incentives were given to participants who completed the intervention successfully. No adverse events were reported during the pedometer-based walking interventions and assessments.

The participant's baseline demographic characteristics are described in Table 1. Significant differences were found between the groups in age and height, but not in other outcome variables. Because the outcome measure BMI is derived from body height and weight, and body height does not influence the IPAQ-SF score directly ${ }^{19)}$, only age was treated as a covariate in the two-way repeated-measures analysis of covariance.

All outcome variables are presented in Table 2. Although no significant time, group, or time-by-group interaction effects were found in the two primary outcomes (all $\mathrm{p}>0.05$ ), trends of improvement were demonstrated exclusively in the smartphone pedometer group. The IPAQ-SF total activity score improved by $9.9 \%$, and the BMI decreased by $0.7 \%$ after the smartphone pedometer-based walking intervention. In addition, the participants in the smartphone pedometer group had a higher average IPAQ-SF total activity score (by 12.4\%) and a lower average BMI (by 4.7\%) on the posttest than the participants in the traditional pedometer group did. The independent t-test result revealed that the average pedometer count over the 2-week intervention period was comparable between the two groups $(\mathrm{p}=0.159)$.

\section{DISCUSSION}

This pilot study showed that both the smartphone pedometer application-based walking intervention and the traditional pedometer-based walking intervention were well accepted by community-dwelling older adults. The smartphone pedometer application seemed to be more convenient than the traditional pedometer, and the risk of losing the pedometer (smartphone) was minimized. Although statistically insignificant, greater trends of improvement in the primary outcome measures-habitual physical activity and BMI - were observed in the seniors who used a smartphone pedometer application than in those who used a traditional pedometer.

Previous randomized controlled trials reported that the use of a smartphone-based application can increase walking in daily life (daily step count) in older and younger adults ${ }^{6,8)}$. It can also motivate sedentary people to increase their physical 
Table 1. Characteristics of participants

\begin{tabular}{lcc}
\hline & $\begin{array}{c}\text { Smartphone pedometer group } \\
(\mathrm{n}=97)\end{array}$ & $\begin{array}{c}\text { Traditional pedometer group } \\
(\mathrm{n}=54)\end{array}$ \\
\hline Age $(\mathrm{yrs})$ & $60.1 \pm 5.5^{*}$ & $65.3 \pm 8.7$ \\
Gender $(\mathrm{n})$ & 46 male $/ 51$ female & 19 male / 35 female \\
Body weight $(\mathrm{kg})$ & $63.0 \pm 10.9$ & $59.5 \pm 13.2$ \\
Body height $(\mathrm{cm})$ & $163.4 \pm 9.2^{*}$ & $158.6 \pm 11.1$ \\
\hline
\end{tabular}

Mean \pm standard deviation is presented, unless specified otherwise.

$* \mathrm{p}<0.05$ compared to the traditional pedometer group.

Table 2. Outcome measurements

\begin{tabular}{lcccc}
\hline & \multicolumn{2}{c}{$\begin{array}{c}\text { Smartphone pedometer group } \\
(\mathrm{n}=97)\end{array}$} & \multicolumn{2}{c}{$\begin{array}{c}\text { Traditional pedometer group } \\
(\mathrm{n}=54)\end{array}$} \\
\hline & Pretest & Posttest & Pretest & Posttest \\
\hline Primary outcome measures & & & & \\
IPAQ-SF total activity score (MET-min/wk) & $2,705.4 \pm 2123.3$ & $2,973.4 \pm 2747.0$ & $2,690.6 \pm 2059.6$ & $2,644.9 \pm 1821.6$ \\
Body mass index $\left(\mathrm{kg} / \mathrm{m}^{2}\right)$ & $23.3 \pm 3.2$ & $23.2 \pm 3.4$ & $23.4 \pm 3.2$ & $24.3 \pm 6.2$ \\
Secondary outcome measure & & & & \\
$\quad$ Average pedometer count (steps/day) & $6,738.5 \pm 3,264.8$ & $10,057.9 \pm 16,103.1$ \\
\hline
\end{tabular}

Mean \pm standard deviation is presented.

IPAQ-SF: International Physical Activity Questionnaire-Short Form.

activity $^{9,24)}$ and reduce the amount of time that overweight and obese individuals spend on sedentary activities ${ }^{7}$. Our findings further show that a smartphone-based application might be even better than a traditional pedometer in increasing habitual physical activity and decreasing BMI, possibly because our participants used the smartphone pedometer application as part of their daily lives and thus showed better adherence to the walking intervention ${ }^{25)}$. In addition, two recent qualitative studies have transcribed positive experiences with smartphone applications to increased physical activity in adults ${ }^{17,24)}$. These favorable experiences might also explain why both habitual physical activity and BMI showed an apparent improvement in the smartphone pedometer group. A summary of the users' positive experiences is given below.

(1) The participants were surprised by their own daily step counts as registered by the smartphone application and were keen to compare their step counts with the recommended daily 10,000-step goal.

(2) The technology made attainment of the daily 10,000-step goal more interesting and motivating.

(3) The participants interacted with the smartphone applications, which provided live feedback on their daily step count.

(4) Many participants had their smartphones in close proximity. The extrinsic feedback of visualizing the step count (instant positive reinforcement) provided a sense of achievement to the participants.

(5) The smartphone applications indirectly encouraged the participants to change their exercise behavior (e.g., to walk around the house in times of inclement weather).

(6) The participants gained confidence and incorporated exercise (walking) into their daily routine to fit their own lifestyle.

(7) The smartphone applications are easy to use and can be tailored to an individual and used independently.

(8) The highly visible always-on smartphone applications made participants aware that their steps were being tracked continually. This self-monitoring technology helped the participants track their exercise (walking) progress and change their behavior to attain the daily 10,000 -step goal ${ }^{17,24)}$.

Not all of these perceived benefits were noted in the participants who used traditional pedometers to increase their physical activity and reduce their $\mathrm{BMI}^{1}$. Therefore, the use of a smartphone pedometer application might be more favorable than that of a traditional pedometer in improving physical activity and BMI in an adult population, including community-dwelling older adults.

No significant difference was found between the two groups in the secondary outcome measure (average pedometer count over the 2-week intervention period). This result was questionable because previous studies have reported that smartphone pedometer applications are less accurate than traditional pedometers in counting steps ${ }^{26)}$ and that the quality of the pedometer applications varies ${ }^{27}$. Further studies should use validated smartphone pedometer applications to confirm the result.

This study has several limitations; therefore, the findings should be interpreted cautiously. First, the free pedometer applications used in this study were not standardized, and their validity and reliability were not known. These pedometer applications may not have been accurate, valid, or reliable in measuring step counts, especially for research purposes ${ }^{28)}$. Second, because the IPAQ-SF total activity score was a self-reported measure of habitual physical activity, it may over- 
estimate the participants' actual physical activity levels ${ }^{19}$ ). Third, women and people with lower weights may have higher daily step counts than men and overweight individuals ${ }^{29}$. We did not consider these two confounding factors in the study design. Fourth, the group assignment was not randomized; some seniors who joined the traditional pedometer group had no experience with smartphones, and those who joined the smartphone pedometer group may have been more willing to adopt technology in their exercise (walking) routine ${ }^{30)}$. Further study should use a randomized controlled study design, include a larger sample, use a longer intervention period and validated instruments, and include a no-intervention control group to better explore the relative effectiveness of smartphone pedometer technology and traditional pedometers in improving the physical activity and health of community-dwelling older adults.

To conclude, smartphone pedometer applications might be more favorable than traditional pedometers in improving habitual physical activity and BMI in community-dwelling older adults. However, further experimental studies are necessary to confirm the results.

\section{ACKNOWLEDGEMENTS}

We thank the University of Hong Kong BSc (Exercise and Health) students for collecting the data and Mr. Gabriel Tsz

Yeung Mak and Mr. Terence Tsz Yu Mak for providing support for the study. This study was supported by the Experiential Learning Fund 2015 granted by the University of Hong Kong Gallant Ho Experiential Learning Centre.

\section{REFERENCES}

1) Bravata DM, Smith-Spangler C, Sundaram V, et al.: Using pedometers to increase physical activity and improve health: a systematic review. JAMA, 2007, 298: 2296-2304. [Medline] [CrossRef]

2) Snyder A, Colvin B, Gammack JK: Pedometer use increases daily steps and functional status in older adults. J Am Med Dir Assoc, 2011, 12: 590-594. [Medline] [CrossRef]

3) Doi T, Ono R, Ono K, et al.: The association between fear of falling and physical activity in older women. J Phys Ther Sci, 2012, 24: 859-862. [CrossRef]

4) Gardner PJ, Campagna PD: Pedometers as measurement tools and motivational devices: new insights for researchers and practitioners. Health Promot Pract, 2011, 12: 55-62. [Medline] [CrossRef]

5) Zoellner J, Powers A, Avis-Williams A, et al.: Compliance and acceptability of maintaining a 6-month pedometer diary in a rural, African American community-based walking intervention. J Phys Act Health, 2009, 6: 475-482. [Medline]

6) Glynn LG, Hayes PS, Casey M, et al.: Effectiveness of a smartphone application to promote physical activity in primary care: the SMART MOVE randomised controlled trial. Br J Gen Pract, 2014, 64: e384-e391 [CrossRef]. [Medline]

7) Bond DS, Thomas JG, Raynor HA, et al.: B-MOBILE — a smartphone-based intervention to reduce sedentary time in overweight/obese individuals: a withinsubjects experimental trial. PLoS ONE, 2014, 9: e100821. [Medline] [CrossRef]

8) Harries T, Eslambolchilar P, Stride C, et al.: Walking in the wild-Using an always-on smartphone application to increase physical activity. In: Kotze P et al. (eds.), INTERACT 2013, Part IV, LNCS 8120. Austria: IFIP International Federation for Information Processing, 2013, pp 19-36.

9) Fukuoka Y, Vittinghoff E, Jong SS, et al.: Innovation to motivation-pilot study of a mobile phone intervention to increase physical activity among sedentary women. Prev Med, 2010, 51: 287-289. [Medline] [CrossRef]

10) eMarketer. Smartphone users worldwide will total 1.75 billion in 2014. http://www.emarketer.com/Article/Smartphone-Users-Worldwide-Will-Total-175-Billion-2014/1010536 (Accessed Dec. 28, 2015)

11) Shim JM: The effect of carpal tunnel changes on smartphone users. J Phys Ther Sci, 2012, 24: 1251-1253. [CrossRef]

12) Kim GY, Ahn CS, Jeon HW, et al.: Effects of the use of smartphones on pain and muscle fatigue in the upper extremity. J Phys Ther Sci, 2012, 24: 1255-1258. [CrossRef]

13) Kim MS: Influence of neck pain on cervical movement in the sagittal plane during smartphone use. J Phys Ther Sci, 2015, 27: 15-17. [Medline] [CrossRef]

14) Lee M, Hong Y, Lee S, et al.: The effects of smartphone use on upper extremity muscle activity and pain threshold. J Phys Ther Sci, 2015 , $27:$ 1743-1745. [Medline] [CrossRef]

15) Lee S, Lee D, Park J: Effect of the cervical flexion angle during smart phone use on muscle fatigue of the cervical erector spinae and upper trapezius. J Phys Ther Sci, 2015, 27: 1847-1849. [Medline] [CrossRef]

16) Fanning J, Mullen SP, McAuley E: Increasing physical activity with mobile devices: a meta-analysis. J Med Internet Res, 2012, 14: e161. [Medline] [CrossRef]

17) Casey M, Hayes PS, Glynn F, et al.: Patients' experiences of using a smartphone application to increase physical activity: the SMART MOVE qualitative study in primary care. Br J Gen Pract, 2014, 64: e500-e508 [CrossRef]. [Medline]

18) Takagi D, Nishida Y, Fujita D: Age-associated changes in the level of physical activity in elderly adults. J Phys Ther Sci, 2015, 27: 3685-3687. [Medline] [CrossRef]

19) Lee PH, Macfarlane DJ, Lam TH, et al.: Validity of the international physical activity questionnaire short form (IPAQ-SF): a systematic review. Int J Behav Nutr Phys Act, 2011, 8: 115. [Medline] [CrossRef]

20) Craig CL, Marshall AL, Sjöström M, et al.: International physical activity questionnaire: 12-country reliability and validity. Med Sci Sports Exerc, 2003, 35: 1381-1395. [Medline] [CrossRef]

21) Visscher TL, Seidell JC, Molarius A, et al.: A comparison of body mass index, waist-hip ratio and waist circumference as predictors of all-cause mortality among the elderly: the Rotterdam study. Int J Obes Relat Metab Disord, 2001, 25: 1730-1735. [Medline] [CrossRef]

22) Ponngeon O, Chaunchaiyakul R, Vareesangthip K, et al.: Home-based walking program increases leg muscle strength in hemodialysis patients. J Phys Ther 
Sci, 2011, 23: 345-348. [CrossRef]

23) White IR, Horton NJ, Carpenter J, et al.: Strategy for intention to treat analysis in randomised trials with missing outcome data. BMJ, 2011, 342: d40. [Medline] [CrossRef]

24) Fukuoka Y, Lindgren T, Jong S: Qualitative exploration of the acceptability of a mobile phone and pedometer-based physical activity program in a diverse sample of sedentary women. Public Health Nurs, 2012, 29: 232-240. [Medline] [CrossRef]

25) Al Ayubi SU, Parmanto B, Branch R, et al.: A persuasive and social mHealth application for physical activity: a usability and feasibility study. JMIR mHealth uHealth, 2014, 2: e25.

26) Boyce G, Padmasekara G, Blum M: Accuracy of mobile phone pedometer technology. J Mob Technol Med, 2012, 1: 16-22. [CrossRef]

27) Chen J, Cade JE, Allman-Farinelli M: The most popular smartphone apps for weight loss: a quality assessment. JMIR mHealth uHealth, 2015 , 3: e104.

28) Orr K, Howe HS, Omran J, et al.: Validity of smartphone pedometer applications. BMC Res Notes, 2015, 8: 733. [Medline] [CrossRef]

29) Cho SH, Oh BD, Cho BJ: Analysis according to gender and body mass index of the number of steps taken by sedentary workers as measured by a pedometer. J Phys Ther Sci, 2013, 25: 919-921. [Medline] [CrossRef]

30) Portney LG, Watkins MP: Foundations of clinical research-Applications to practice, 3rd ed. New Jersey: Pearson Education Inc., 2009. 